
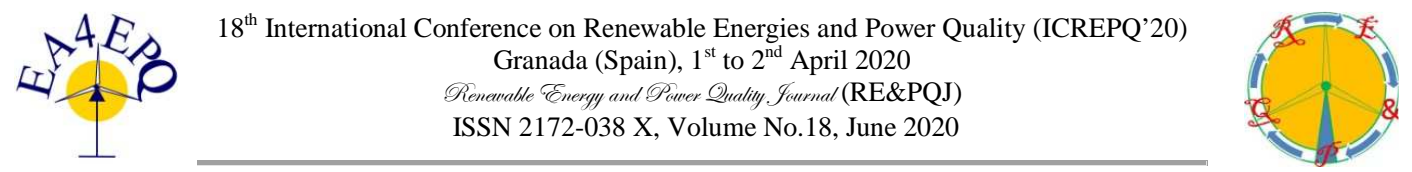

\title{
Agile Application Landscape Planning in Energy Sector - Architectural Experiences
}

\author{
I. Vokony ${ }^{1}$, M. B. Szekeres ${ }^{1}$ and V. Gy. Nemeth ${ }^{1}$ \\ ${ }^{1}$ Strategy and Architecture Enterprise Architecture Management \\ E.ON Digital Technology Hungary \\ Váci str. 17., Budapest, 1134, Hungary \\ Phone/Fax number: +36 30 7903997, e-mail: istvan.vokony@eon.com
}

\begin{abstract}
The continuously changing and developing technology framework and IT infrastructure create novel approaches and possibilities all over the industry spectrum. Thus the energy and its IT supporting segment cannot be an exception either. Nowadays it is hard to imagine any kind of work process on energy generation, transmission, distribution or consumption filed without IT application solutions. To keep this portfolio transparent and effective a methodology is needed for developments and strategy planning.

In this paper enterprise application landscape planning experiences and recommendations are introduced. The approach effectively combines the TOGAF (The Open Group Architecture Framework) and Agile methods.

At the end of a five years 'journey', the evolution can be followed from a target architecture planning approach to a novel solution which is in use right now.

To conclude this work a group of techniques and methods are suggested for the application of these solutions for a sustainable and forward-looking application portfolio at a reasonable cost level.
\end{abstract}

Keywords. Grid layers, application portfolio, TOGAF, agile method, energy revolution

\section{Introduction}

The evolution of technology and science is the key to prosperity. Technological development is in its fourth wave of revolution - after the previous ones connected to the steam engine, electricity and computer/IT technology. This revolution affects every connecting industry, including the energy sector. New solutions, sensors, devices are available but the main question is how to utilize these assets. The so-called smart grid technologies have many advantages but also present challenges [1].

Digital transformation and its effects significantly change the approach of supporting the energy distribution core functionalities. Nowadays, it is almost impossible to solve any task or complete a simple work phase without a computer or a handheld IT device, to get the location, work order description, parameters etc. To operate and plan for the long term, an appropriate architecture and design framework is crucial. Enterprise architecture management within large companies typically covers a very complex scope of activities [2]: business, IT, and organization information infrastructure. The role of enterprise architecture within a developing and growing company will become increasingly important [3].

In this paper an application landscape evolution and its experiences are introduced, based on a new, agile approach to consolidate and make the application portfolio itself more effective. The existing capabilities were collected and handled scientifically instead of 'so we do' approach to ensure high quality services and business continuity. Furthermore, via a specific example a new methodology is described to plan the application landscape taking into consideration the continuously changing hard technology and IT environment.

\section{Overview and background}

In most of the studies [4], expert interviews were conducted to investigate various cases of enterprise architecture management use. Many articles [5] highlight the need for application mapping and the fact that this is an existing process for most companies Consequently, there is a unified register of applications and some level of visualization of them for almost all large companies. The question is whether the list and the visualization are supported by different or the same enterprise architecture management tools.

A more advanced solution was experienced in an energy company, namely E.ON Digital Technology Hungary. Basically, they keep track of applications with IT support. First, the records were cleaned up, missing data were filled in, and inconsistencies, such as format discrepancies were corrected. At a later stage of the process, the business capabilities were also recorded, and based on the existing hierarchy, application capability mappings were also performed. Interface capture was also planned, and the latter was temporarily solved by expert manual interviews with a tabular collection. The temporary nature of the solution is an important cornerstone, which we will return to later.

The repository is theoretically equivalent to a single data dictionary, but data is typically not up to date. Our proposal is not aimed at collecting data sources or automating data loading, but to formulate guidelines, specifically for the modeling process. In other words, a solution is needed on how to make the most of existing 
data and create views that meet the needs of stakeholders to a considerable degree.

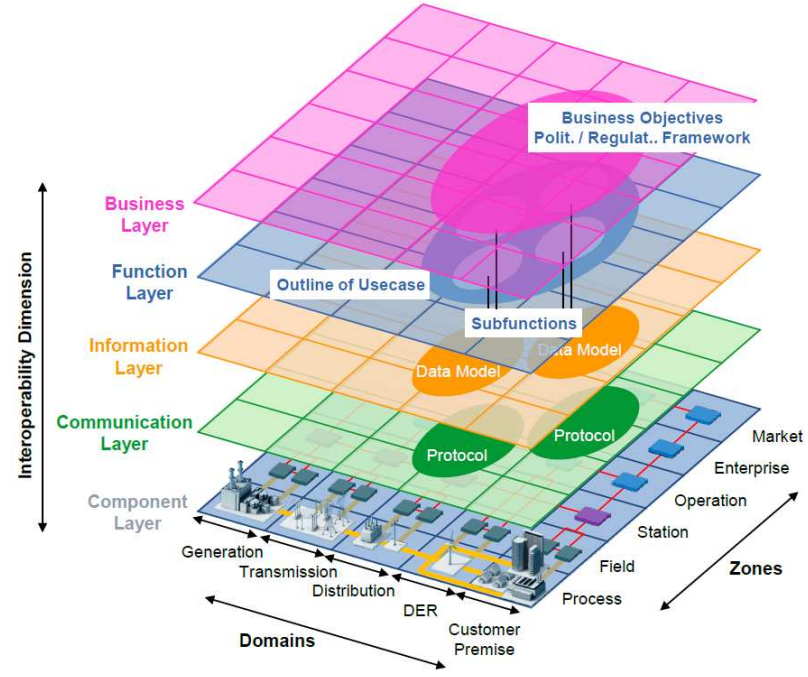

Fig.1. Overview of the SGAM (Smart Grid Architecture Model) [6]

As it can be seen in Figure 1, there are at least 5 layers in distribution dimension affecting the application portfolio at many business areas from energy network to corporate subsystems [7]. If at any point of the architecture a replacement, refreshment change or a single new application is integrated, the multi-affect results are hard to predict or just to follow [8]. Consequently, from an IT point of view it was important to avoid the operational challenges at a reasonable price level in order to change the traditional landscape planning approach and establish a new methodology. The IT development changed planning and portfolio handling from waterfall to agile without damaging business continuity.

\section{Methodology}

There are several pillars and building blocks of enterprise architecture. For example, an application architecture is an important layer that includes applications, systems, and interactions between them. The transparency of the application architecture can become a critical factor for the management [9]. The most common mistake is the systematization of information and the lack of transparency. To avoid these problems, an appropriate methodology and toolset should be chosen. In this project, the TOGAF and the Agile approach were chosen.

\section{A. TOGAF}

Creating an application map or application landscape can appear in several process steps. The first requirement is to create the as-is version, which is a current 'map' of the company's IT applications. Afterwards, the development of the to-be version is typically based on the availability and usability of the as-is map, and on the other hand, also on the business and IT strategic decisions, i.e. requirements. To determine what goals we want to reach, we need to know our business and IT directions - the application map is only a supporting tool for these.

TOGAF - which is the abbreviation of The Open Group Architecture Framework - is probably the most popular EA (Enterprise Architecture) framework among companies in the last decade. It is a large collection of best practices in enterprise architecture, thus it is formulated by the know-how of several corporations, within the energy sector as well.

There are various EA analysis techniques, as defined by TOGAF, that can also be used to evaluate an application map. In addition to difference analysis and conformity testing, there are many methods at our disposal. We can use, for example, consolidated gaps, dependency matrices, architecture state evolution tables, governance logs, and various maturity models to refine and improve our map [14].

TOGAF formulates basic guidelines for each of these layers. The application guidelines are technology independent and easy to use. According to the former, applications are independent of specific technology choices and therefore can operate on many technology platforms. The transparency of the technology makes the system easy to use, so the user can concentrate on the tasks and interactions performed. All in all, we can see that these two policies encourage users to work in an integrated information environment rather than using separate systems. All these principles have many implications, and some of them will be discussed later [10].

\section{B. AGILE}

Business Agility is one of the most fashionable operational and cultural directions these days. Basically, it is applied to promote collaboration in segmented, sometimes "silo"-like organizations, to structure delivery by breaking down complex, long term plans into tangible, well definable increments, which requires and promotes more detailed short term requirement definition. As many energy and utility firms have a long lasting tradition of 510-year-long network development concepts and 3-yearlong projects, the adaptation of Business Agility is picking up relatively slowly in this industry. However, if the subject activity is well chosen, the above mentioned elements can bring attractive results both in cultural and investment regards. Further on, Agile development portfolio-management solutions aid the improvement of transparency, as they require single-file prioritization of development initiatives, ensuring that a comprehensive resource, architecture and time planning takes place, involving all stakeholders [12].

To give an idea of how to involve enterprise architectural aspects into business value proposition design and initiation, let us discuss how information, stakeholders and methods are managed to achieve that.

In the earliest stages of business value proposition definition, the customer oriented goals of the entities are translated into short, concise but comprehensive value proposition statements, aided by adequate templates. To present the actual project idea in a way that ensures a high priority to the task at hand, the topic owner has to cover all the angles of the planned development, even if initially at a very high level [13]. The collection of such fundamental information also involves discussions with enterprise architecture specialists to verify the necessity of any technological improvement, to make sure no parallel system structures are implemented, or to put it differently, to check the availability of any existing 
(fitting or applicable/adjustable) solution, to prevent duplications. In a well-managed Agile portfolio selection process, no initiative is launched without this preliminary architect assessment.

The next instance of architectural involvement is the resource planning chapter, as it is the senior enterprise architecture professionals who are able to estimate the nature and quantity of skills needed for the actual development initiative.

During design, and also in all Agile sprints of delivery (continuous deployment), the actually developed piece of functionality has to fit into the existing application landscape and at the same time, meet the time and scope requirements of the business. As mentioned earlier, risking business continuity is not acceptable. This phase-by-phase architectural fit also has to be verified by enterprise architects.

Another positive result of bringing Agile culture into operation besides applying Agile methods is the strengthening of collaboration, making also architecture an integral part of business value based developments. Agile stakeholder management requires involving all collaborators and decisionmakers early on, to ensure the best possible preparation of the organization for the implementation.

To look a bit further, the above mentioned activities should be repeated regularly, multiple times a year. Which means, the opportunities for failure to fit the new increment into the existing landscape are more frequent than before. This brings us to one of the most complex and strategic activities of the architecture team: to define development goals, areas and roadmaps. We cannot emphasize the importance of this step enough, as the 'big picture' cannot be missing. Imagine yourself completing a puzzle adding pieces month by month, or quarter by quarter, without knowing what it shall depict, only paying attention to the bits fitting together. Or to give another gamified example, you could create anything of fitting building blocks without considering a blueprint.

Agility is often misused to decrease planning efforts. This is the biggest possible mistake in applying the methodology. You very much need to plan the features, interfaces, connections, dependencies and resource needs of each development increment. The only upside is, you do not have to do it all at once.

To sum up, in a complex IT system landscape, it always pays to consider and know 3 factors:

1) existing landscape

2) mid- to long term development objectives

3) the logical structure of adding new elements into the existing pool of solutions.

\section{Results and discussion}

In the present 5-year-long project many steps were made to achieve the present maturity of our architectural operation. The main steps are introduced below and the results are shown, from basic application repository solution, through a complex screening project, via a system frontend middleware and backend investigation to capability mapping. This was the point where the IT approach and business goals could strengthen each other and commonly draw the to-be vision as a platform operation.

\section{A. TOGAF approach}

According to TOGAF, the different layers of architecture have a lot of interactions with each other [11]. The Enterprise Architects at our company had to consider these behaviours during the landscape creating process. Generally, there is a multiple-step process which results in the business, the information system and the technology architecture deliverables. At first, we needed to select the reference models, viewpoints and tools. After the selection, the baseline architecture description was created, to which the target architecture description could be compared. While the baseline architecture description is usually a high-level classification of the components, the target architecture already might contain a complete documentation for each component. The latter is needed to clarify new architecture elements and to integrate them with existing ones. To compare the baseline and the target state, gap analysis is required to make sure that the transition is feasible. During gap analysis, we highlight each change that we plan to make to the baseline architecture. In addition, we created socalled blueprints, which are interim landscapes that help in understanding the transition phases and prioritizing the candidate building blocks.

The next steps in the process are to define the components of the roadmap and to conduct impact assessment within the whole landscape. Once these are done, stakeholders formally comment on outputs, determine the final state of the architecture, and provide the necessary documentation.

The above-mentioned process defines the approach of mapping the distinct architecture layers. However, these layers constitute a smaller part of the Architecture Development Method (ADM) which is the core of the TOGAF approach. Furthermore, TOGAF has a proposal for applying the ADM across the whole architecture landscape. According to the proposal, a landscape has four main characteristics: breadth, depth, time, recency. Three of these are represented by the figure below.

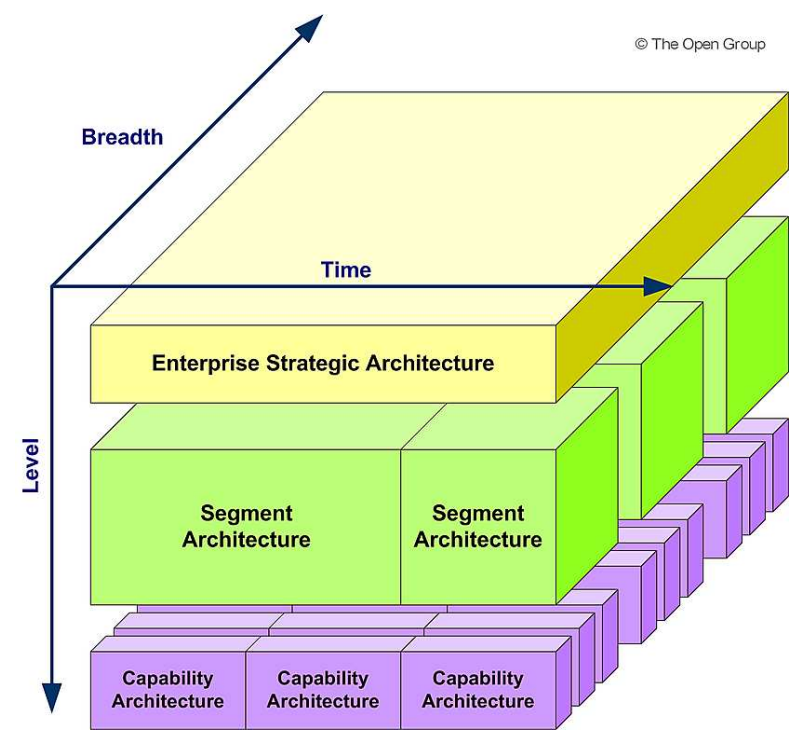

Fig.1. Summary Classification Model for Architecture Landscapes [14] 


\section{a. Breadth}

This factor was considered right at the beginning, when we started the first discussions with the stakeholders within the company. It is important to have a high level approach first to facilitate the way towards better granularity. If a strategic decision needs to be prepared, the proposal is a holistic view about the applications or the application groups [15]. This is equal to a management-level deliverable from an architecture perspective.

Our first application landscape was more detailed, defined by the segment architecture level: the used information systems were grouped by the segments, namely Energy Networks, Customer Solutions and Corporate (in this paper the focus is on Energy Networks.)

\section{b. Depth}

If specific subject areas are examined, more detailed models are needed than in the case of more comprehensive areas.

\section{c. Time}

As it was mentioned previously, more target architecture plans can be created for different points in time. In most cases, long-term target pictures can be created only at a holistic level [16]. If we would plan with more details e.g. distinct information systems or modules -, then it is almost impossible to predict the long-term state of the architecture.

The mostly used and suggested time period for measuring architectural changes is years. However, as we move forward in time, we need to be aware of using the right level of granularity.

\section{d. Recency}

The greatest issue for large corporations is that the application landscape is not always well-maintained. An up-to-date model helps to monitor the state of the transition from the baseline to the target landscape, and from the actual to the planned state of gaps state as well.

Besides the previously detailed TOGAF procedure, we had a parallel running project focusing on architecture risk management, contributing significantly to the to-be planning process. The risk assessments can show whether retirement of the applications is required [17].

There is one really important factor regarding recency: using TOGAF ADM method is not equal to a waterfall approach. The architecture landscaping is required to be completely iterative in order to gain efficiency and transparency across the enterprise [18].

\section{B. Capability approach}

During the evolution of application landscape transparency and planning the methodology based TOGAF solution [19] was 0 . The other was the capability-based approach. On the one hand, the inventory of applications, hardware, interfaces, etc. can be compiled, but the question is still open: is it optimal? Do we have enough/too much/etc. applications for the business purpose? To validate and rise the opportunity for consolidating the application portfolio the capability-based approach was the key. In our study the Energy Network applications are in focus.

At least in three levels can be differentiated and broken down to usual and necessary capabilities in energy utility industry [20]. Most of them are present and supported by any kind of application. Furthermore, there might be some business processes which are supported by an IT application and quite difficult to align with the dedicated level 1 capabilities. Of course industrial specific solutions may exist, but taking the methodology seriously, all of them can be matched.

At least for level 1 capabilities the landscape may be complete, with the breakdown resolution being different for individual capabilities [21]. If the process follows the methodology and premises concepts, the two approaches should cover each other. The catalogue creation and the capability survey should result in the same application landscape, only the approach and the formulation should be different [22]. After the first results, the validation was the next step [23]. Fortunately the data collection and clustering processes proved to be perfect and the landscapes were the same independently from the creation approach. After the first validation checkpoints, the real added value could be harvested: which business areas and processes are in lack of appropriate IT support, where should a consolidation project be established and which departments operate well. These reports can be generated quite easily with the help of this exploration.

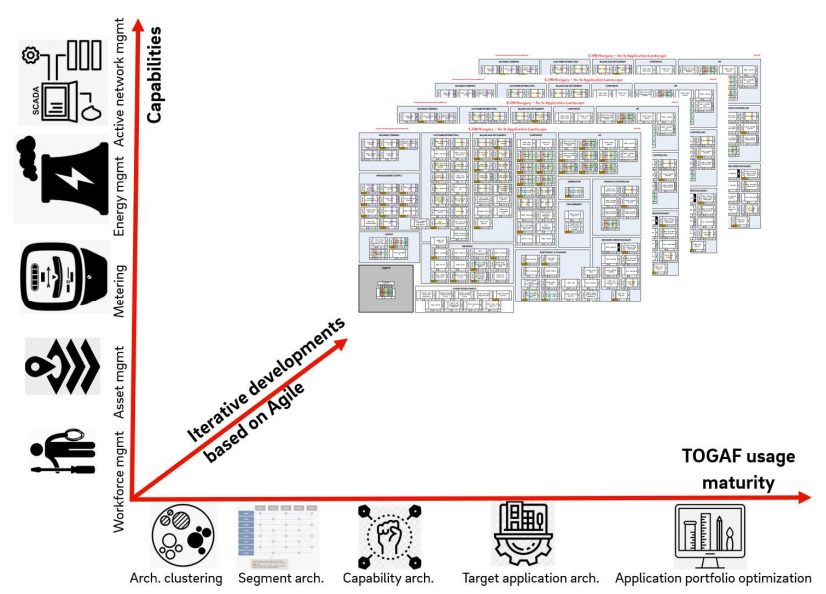

Fig.2. Capability based application landscape exploration

At this point major conclusions and evaluation were necessary to be drowned, to plan how to utilize these results in operation in the future. One keen point was the input data refreshment [24]. During the research, much of the data was collected manually, but in the long run it is not a sustainable solution. To solve this issue, an enterprise IT cataloguing software and additional workflows were established and defined to assure errorfree and automatic data refreshment [25].

It is worth mentioning that after the first evaluation of this survey, another action was defined: based on the architectural information, the cost structure should be analysed too and defining the possible risks and their mitigation in 6 categorizes (hardware, support, infrastructure, etc.) to prepare a heatmap from the landscape.

The first results were more than promising and the plan was elaborated to keep this activity productive in midterm [26]. But the evolution of the landscape is the most important part of the IT application planning and strategy creation. Agile portfolio planning is the key for that. Regularly, all of the influential requirements of the 
architecture are listed, analysed and the effect to the architecture is under review. These requirements are fulfilled with only such solutions which are aligned with the architect community and are in line with the mid- and long term IT strategy in regional and international perspective.

\section{Conclusions and remarks}

In this study, two different approaches were worked out to identify the application landscape and analyse the action points were developments are needed for a large company in the energy sector. The TOGAF based approach was the key for the application catalogue preparation. The capability based approach covered all the supported and to-be-supported business activities. The two approaches must provide the same application landscape just from another viewpoint.

With an appropriate IT architecture, the strategic targets and planning are more tangible and possible to handle. The development method assures keeping the achieved architecture: Agile based IT-portfolio handling can assure that only architecture compliant solutions are developed.

As the next step, a technology guideline is in preparation on the most important fields (application development, hosting, dev-ops etc.) to give appropriate technical support for all the stakeholders who have an impact on the architecture evolution and to create a baseline for the architect community to establish a governance body.

\section{Acknowledgement}

The authors would like to thank Brigitta Popovicsné Koncsos, Managing Director of EDTHU, for supporting the strategy and architecture team. Without continuous follow-up, ideas, and constructive questions, this process would not have kept where we are today.

\section{References}

[1] Sergej Bondara, John C. Hsub, Alain Pfougaa, Josip Stjepandića, "Agile Digitale Transformation of Enterprise Architecture Models in Engineering Collaboration", 27th International Conference on Flexible Automation and Intelligent Manufacturing, FAIM2017, (2017)

[2] Sergej Bondar, John C. Hsu, Alain Pfouga, Josip Stjepandic, "Agile Digital Transformation of System-of-Systems Architecture Models Using Zachman Framework", Journal of Industrial Information Integration (2017)

[3] Mathias Uslar, Sebastian Rohjans, Christian Neureiter, Filip Pröstl Andrén, Jorge Velasquez, Cornelius Steinbrink, Venizelos Efthymiou, Gianluigi Migliavacca, Seppo Horsmanheimo, Helfried Brunner, Thomas I. Strasser, "Applying the Smart Grid Architecture Model for Designing and Validating System-ofSystems in the Power and Energy Domain: A European Perspective", Energies (2019)

[4] Nowakowski, E. - Farwick, M. - Trojer, T. - Häusler, M. Kessler, J. - Breu, R., "Enterprise Architecture Planning: Analyses of Requirements from Practice and Research", Proceedings of the 50th Hawaii International Conference on System Sciences (2017)

[5] Khosroshahi, P. A. - Hauder, M. - Volkert, S., "Business Capability Maps: Current Practices and Use Cases for Enterprise Architecture Management", Proceedings of the 51st Hawaii International Conference on System Sciences (2018)

[6] Smart Grid Coordination Group. Smart Grid Reference Architecture; Technical Report; CEN-CENELEC-ETSI:
Brussels, Belgium, 2012.

[7] Jessica Díaz, Jennifer Pérez, Juan Garbajosa, “Agile product-line architecting in practice: A case study in smart grids", Information and Software Technology 56 (2014)

[8] Imane Worighi, Abdelilah Maach, Abdelhakim Hafid, Omar Hegazy, Joeri Van Mierlo, "Integrating renewable energy in smart grid system: Architecture, virtualization and analysis", Sustainable Energy, Grids and Networks 18 (2019)

[9] Jacques Palicot, Christophe Moy, Benoit Resimont, Remi Bonnefoi, "Application of Hierarchical and Distributed Cognitive Architecture Management for the Smart Grid", Ad Hoc Networks (2015)

[10] Szekeres, M. B., "Application Architecture Modeling in the Energy Sector in a corporate environment", MsC Thesis (2019)

[11] Maulana Ibrohim, Abba Suganda Girsang: Designing IT Blueprint with TOGAF for Information Technology Development. International Journal of Mechanical Engineering and Technology 10 (2019)

[12] PMI Hungary: “AGILIS Gyakorlati Útmutató - A practical guide to Agility (2019)

[13] Nemeth, V.Gy.: Hungarian Agile Transformation Panorama 2019/1 - LinkedIn.com - (2019)

[14] The TOGAF Standard, Version 9.2. Applying the ADM Across the Architecture Landscape. (2018)

[15] M. Pulkkinen: Systemic Management of Architectural Decisions in Enterprise Architecture Planning. Four Dimensions and Three Abstraction Levels, Proceedings of the 39th Annual Hawaii International Conference on System Sciences (HICSS'06)

[16] Steven Spewak Michael Tiemann: Updating The Enterprise Architecture Planning Model, Journal of Enterprise Architecture - May 2006

[17] Dinesh Kumar: It services architecture planning and management, United States Patent Application Publication Dec. 13,2007

[18] Jan Saat, Stephan Aier, Bettina Gleichauf: Assessing the Complexity of Dynamics inEnterprise Architecture Planning Lessons fromChaos Theory, Americas Conference on Information Systems 2009

[19] Col Perks, Tony Beveridge: Guide To Enterprise IT Architecture, Springer 2003

[20] Christian Schmidt, Peter Buxmann: Outcomes and success factors of enterprise IT architecture management: empirical insight from the international financial services industry, European Journal of Information Systems, Volume 20, 2011

[21] Jeanne W. Ross: Creating a Strategic it Architecture Competency: Learning in Stages, MIT Sloan Working Paper No. 4314-03; Center for Information Systems Research Working Paper No. 335, 2003

[22] Robert Winter, Joachim Schelp: Enterprise architecture governance: the need for a business-to-IT approach, ACM Symposium on Applied Computing 2008

[23] James E. Cates, Sam S. Gill, Natalie Zeituny: The Ladder of Business Intelligence (LOBI): a framework for enterprise IT planning and architecture, Int. J. Business Information Systems 2005

[24] Bernard H: Boar: The Art of Strategic Planning for Information Technology (second edition), Wiley Computer Publishing, 2001

[25] Lars G. Bratthall, Robert van der Geest, Holger Hofmann: Integrating hundred's of products through one architecture: the industrial IT architecture, 24th International Conference on Software Engineering, 2002

[26] Åsa Lindström, Pontus Johnson, Erik Johansson, Mathias Ekstedt, Mårten Simonsson: A survey on CIO concerns-do enterprise architecture frameworks support them?, Information Systems Frontiers, Volume 8, Issue 2, pp. 81-90, February 2006 